\title{
Current Situation and Development Trend in Thermal Insulation Coatings
}

\author{
Hui ZHANG ${ }^{1}$, Fei WANG ${ }^{1,2 *}$, Jin-Sheng LIANG $^{1,2}$, \\ Qing-Guo TANG ${ }^{1,2}$, Zeng-Yao SHANG ${ }^{1}$ \\ ${ }^{1}$ Institute of Power Source \& Ecomaterials Science, Hebei University of Technology, \\ 300130 Tianjin, China \\ ${ }^{2}$ Key Laboratory of Special Functional Materials for Ecological Environment and Information, \\ Hebei University of Technology, Ministry of Education, Tianjin 300130, China \\ *wangphilip@yeah.net
}

Keywords: Current situation, Development trend, Thermal insulation; Coatings; Fillers

\begin{abstract}
Thermal insulation coating has attracted more and more attention because of the advantages of economic, construction convenient and good heat insulation effect, and it will be expected to promote the development of coatings market and heat insulation materials applications. Based on the above reason, current situation of thermal insulation coatings was briefly reviewed and discussed, and the research orientations related to thermal insulation materials were also proposed.
\end{abstract}

\section{Introduction}

At present, the vast majority of construction in China is high energy consumption and non energy-saving buildings. The units of energy consumption in China is up to 3 times as much as new construction in developed countries which with similar climate. Ministry of construction statistics show that newly built construction area of Chinese urban and rural construction is nearly 2 billion square meters per year, of which more than $80 \%$ is high energy consumption. The existing buildings have nearly 40 billion square meters and high energy consumption buildings are up to more than $95 \%$. In our country, the new building has been basically designed according to the energy saving standard, with the high proportion of $95.7 \%$, but the proportion of execute the energy saving design standard in construction stages is only 53.8\%. Therefore, the problem of building energy conservation has been paid more and more attention. The first "Public building energy efficiency design standards" of China has been formally implemented since July 1st, 2005. Recently, "Development of the construction industry in 12th Five Year plan" has been defined the goal of building energy conservation of our country during the "12th Five Year Plan" period. The strive to achieve the unit area energy consumption of public building is decreased by $10 \%$, large public building energy consumption is decreased by $15 \%$, practical improve the proportion of solar energy, shallow geothermal energy, biomass energy and other renewable energy in the consumption energy of construction at the same time. Aiming at the current state of environmental protection and energy saving requirements, building heat insulation coating has attracted more and more attention due to the advantages of economic, construction convenient and good heat insulation effect, so that the development prospects will be bright. It will be expected to promote the development of coatings market and heat insulation materials applications.

\section{Research Status of Heat Insulation Coatings}

The heat insulation coating was generally composed by the base material which have bonding role, heat insulation material, pigments and auxiliary [1-2], and there are mainly three types of heat insulation coatings has been researched. The heat insulation mechanism and the way of heat insulation of them are different, and the application occasions and heat insulation effects are different. 
Heat transfer is achieved by three ways of convection, molecular vibration heat conduction and heat radiation. Barrier type heat insulation coating is achieved the heat insulation effect through the significant impedance heat transfer. Material heat insulation performance is mainly depend on the thermal conductivity of the material, the heat insulation performance of coating is decided by the size of thermal conductively which added aggregate, and the smaller the thermal conductivity, the better the heat insulation performance [3-6]. This type of coating is usually use materials which with small apparent density, loose internal structure, high porosity and low water content as lightweight aggregate, such as natural porous material and fly ash floating beads etc. It can be combined together depending on the role of the binder and the auxiliary agent, and achieved the effect of heat insulation by directly coated on the surface of the wall or equipment.Barrier type heat insulation coating has the advantages of simple production line, less investment, good economic benefit, directly brushing, convenient construction, good heat insulation effect and so on. However, the coating has big problems of poor impact resistance, low bond strength, and the construction is affected by seasons and climate. Thus, protective layer and waterproof layer should be used in order to form a stable heat insulation system. Yan et al. [7] fabricated a water-based heat insulation coating with thermal conductivity of $0.067 \mathrm{~W} /(\mathrm{m} \cdot \mathrm{k})$ by meas of surface treatment and granularity selection for natural light mineral as aggregate. Li et al. [8] treated expanded perlite, sepiolite and asbestos fiber by means of crushing and surfactant treatment and prepared the heat insulation coating using high speed dispersing and addtion of auxiliary. They found that heat insulation coating as-prepared has good thermal insulation performance after adding the pearlite, asbestos fiber, sepiolite and the town of gouache, and the thermal conduction is $0.06 \mathrm{~W} /(\mathrm{m} \cdot \mathrm{k})$. Cagliostro et al. [9] developed a silicone paint with good waterproof and heat insulation, using the chemical vapor evaporation technology. The organic component of organic silicon solution can be evaporated, leading to the better effect of water resistance and heat insulation of the coating. Thermo-shield ceramic heat insulation coating made in German was mainly composed of tiny vacuum ceramic beads and appropriate environmental protection type emulsion, and it be achieved the heat insulation goal by directly coated on the base material surface with $0.3 \mathrm{~mm}$ thickness. The tesing for civil building by Moorhouse laboratory of the United States shows that the air conditioning energy consumption can be saved at least $64 \%$ in summer [10]. Nelson et al. [11] developed a kind of water-based coating with excellent heat insulation performance, using maleic acid two butyl acetate acetic acid ethylene copolymer as coating film forming materials. Zhang et al. [12] prepared nanostructured zirconia coating on the GH33 substrate by the means of atmospheric plasma spraying. The microstructure of the coating was analyzed by scanning electron microscope and transmission electron microscope, and the results showed that the coating was mainly composed of particle phase wrapped by melting phase, which is beneficial to improving the heat insulation effect of coatings.

In general, the solar radiation spectrum is mainly divided into three spectral regions, and they are ultraviolet, visible and near infrared region. From the energy distribution spectrum of sunlight, it can be seen that solar energy mainly concentrated in the $0.4-1.8 \mu \mathrm{m}$ wavelength in the visible and near infrared region. Thus, the developed reflective type heat insulation coating should have high reflectivity of solar radiation in this wavelength range, in order to obtain the better heat insulation effect of the coating. Beijing Guobang technology development center developed a kind of thin layer heat insulation coating using silicone acrylic emulsion and other water-based polymer materials as the base material, and the heat insulation coating with high solar thermal reflectivity and low thermal conductivity could be prepared by adding some hollow ceramic beads as functional fillers[13]. Guo et al. [14] developed the polyurethane modified high vinyl chloride resin reflective coatings, and they found that the heat reflectivity of coating have a great relationship with the binder of finish, refraction coefficient of pigments and fillers, filler particle size, purity, the thickness of the film and PVC value. Ma et al. [15] prepared a kind of solar heat reflective heat insulation coating, which was composed of the surface layer and the bottom coating. The surface coating contained rutile titanium dioxide, and the bottom coating mainly composed of heat insulation filler of hollow float beads, hollow inorganic fiber and cellulose. An patent from USA [16] introduced a type of infrared reflective coating, using water soluble acrylic resin as the base material.The fillers were mainly 
composed of titanium pigment, red iron oxide, chrome black, talcum powder and mica powder, and the reflectivity of coating on the $1.2-2.0 \mu \mathrm{m}$ infrared was greater than $50 \%$. A Japan patent [17] proposed a reflective ceramic filler composed of titanium dioxide, zinc oxide, magnesium oxide and other metal oxides. The filler particle size was below $1 \mu \mathrm{m}$ and with the characteristic of low thermal conductivity and small specific heat, leading that the solar heat could be reflected effectively. Kiik et al.[18] developed a high heat insulation efficiency coating with $65 \%-100 \%$ of solar reflectivity, by using metal pigments, aluminum sheet, fly ash, ceramic beads as main fillers. At present, the sol-gel method was gradually applied in the field of thermal insulation coating, the prepared coating with high transmittance of visible light and high reflectivity of infrared band was prepared using transparent material as the base material [19-20].

The radiation type heat insulation coating converted the absorption of ultraviolet, visible light and near infrared light energy into heat energy, and passed through atmospheric infrared window in 8-14 $\mu \mathrm{m}$ band by means of infrared radiation. The radiation type heat insulation coating could emit the absorbed heat in the form of heat emission, thus prompting the cooling rate inside and outside of the coating at the same rate [21-22]. At present, the coating was mainly used in the high temperature environment such as steel making and metallurgy, which could greatly improve the radiation coefficient of the object and achieve the saving energy and efficiency increase. Studies have indicated that substance with inverse spinel structure materails mixed by some compounds had the high thermal, which can be used as the filler of energy saving and heat insulation coatings. Wang et al. [23] prepared the heat insulation coating, using glass beads, ceramic beads, titanium pigment and infrared powders as main function fillers. They found that the infrared radiation capability of the coating can be improved greatly when the mass fraction of the infrared powder addition was $3 \%-4 \%$, and the radiation rate of the coating can reach up to 88\%. Wang et al. [24] developed the indium tin oxide powders with a lower infrared emissivity by co-precipitation method, and the collagen indium tin oxide composite coating with infrared low emissivity can be obtained. Luo et al. [25] proposed a water-based waterproof heat insulation coating, using kaolin as the main filler. They found that the coating had characteristics of low thermal conductivity and good waterproof performance, and the radiation rate could be up to $76 \%-88 \%$. Loutfy et al. [26] used fullerene to prepare novel heat insulation materials, and the micron grade fullerene thin film with low thermal conductivity and high emissivity could be used to reduce the temperature of base layer obviously at $800^{\circ} \mathrm{C}$. The HRC radiation coating was devoloped base on chromite as the main filler, and the emission rate was greater than 0.85 in the range of $600-1300^{\circ} \mathrm{C}$ and up to 0.95 in $800^{\circ} \mathrm{C}$, which can be used for five years without damge of lining [27]. Ishihara et al. [28] prepared the thin film with good infrared shielding effect and high transmission rate in visible region, using antimony tin oxide, nano indium tin oxide and some semiconductor nano particles. The nano particles can be used in the coating, and the coating could have transparency and isolated from infrared function, leading to transparency and heat insulation performance at the same time.

\section{The Main Factors of the Heat Insulation Performance of Coating}

Heat insulation coating has the characteristic of coating material and heat insulation material, which is a kind of energy saving and environmental protection coating. The main factors affecting the performance are the base materials and fillers added in coating. Base materials as one of the important components of the coating are important sources of excellent adhesion, water resistance and weather resistance of coating. Base materials can be classified as pure acrylic resin, silicone acrylic resin, epoxy resin, alkyd resin, etc., and they have different performance. As the base material of the heat insulation coating used for the external wall, the reflectivity and the absorption rate of the base material should be considered at first. The base material generally required high transparency, the absorption rate of solar heat should be low, and the energy abosorbing group of structure should as less as possible [29]. In addition, the use of coating should combine with environmental requirements. If the coating was used in building external walls or roof, it should use water-based film as forming material, considering long-term exposure to sunlight and the requirements of economic and 
environmental protection. For example, acrylic resin was often used as a base material for this kind architectural coatings, which has the characteristics of high transparency, strong weather resistance, good adhesion and chemical stability. On the other side, some high molecular resin of coating base material may occur local molecular chain rupture, leading that the coating surface may appear the powder phenomeno under the condition of long-term exposure to the sun and rain. Fortunately, we can get the new coating surface again after the rainwash [30].

Different types of heat insulation coating has different selection of pigments and fillers, and the influence of pigments and fillers on the heat of the sun is mainly reflected in the following aspects. First, the color of an object is produced by visible light reflection, and the object shows white if there is a total reflection when the light illuminate on the surface of the object. When all the incident light is absorbed, the object shows black. Between the two of above, a part of the light is absorbed, a part is reflected or transmitted, then the material shows a variety of colors. Therefore, the main reason for the color of the object is the selective absorption of light by object. The absorption of light of white or near white opaque material is small, so white or close to white pigment should be chosen. Second, the measurement of the reflectivity of the thermal reflection coating can be represented by the scattering rate. The higher the scattering rate is, the more reflected energy is. The scattering rate $\mathrm{M}$ can be defined as the ratio of the refractive index between fillers and base material. It can be concluded that the scattering rate of the coating increases along with the difference increase of refractive index between fillers and base material, thus the fillers with high refractive index should be selected. In addition, the particle size of fillers will also have some influence on the reflective properties of the coating. When the particle size and the wavelength of the light is not the same order of magnitude, the rayleigh scattering is occurred. The Fresnel reflection is occurred while the same order of magnitude exists between the particle size and the wavelength of the light. Meanwhile, the reflection efficiency is the highest [31]. Third, the heat transmission capacity is strong for the materials with high thermal conductivity, and the ability of heat insulation is weak. The barrier type heat insulation coating should add the lightweight porous material, which could play an active role in heat insulation due to the decrease of heat transmitted into the internal coating. There are many materials with the porous and hollow structure, such as sepiolite, diatomite, hollow glass beads and floating beads etc.

\section{Development Trend of the Heat Insulation Coating in the Future}

Multi functional composite heat insulation coatings should be developed and produced. A coating with good heat insulation effect is generally resulted from two or more heat insulation mechanisms at the same time, because each heat insulation coating has its own advantages. The synergy effect of barrier, reflection and radiation should be fully played, considering the characteristics of anti-corrosion, waterproof at the same time. On the above basis, the preparation of multifunctional composite heat insulation coatings with excellent performance could have an significant influence on the development of heat insulation coatings. On the other hand, new heat insulation coatings and related technologies should be explored actively combined with the development and application of nano functional coatings, such as low radiation heat transfer coating, high efficiency thin layer heat insulation and corrosion protection integrated coating, vacuum thermal insulation coating, etc.

At present, the heat insulation coating is only suitable for coating on the outer wall or roof insulation layer, and play a role of heat insulation and protection. They are not able to use as a replacement of the currently widely used external heat insulation system of expanded polystyrene board or polystyrene particles insulation slurry, thus the compound use of heat insulation coating and other thermal insulation materials should be regarded as an important development direction. Moreover, "three wastes" should be utilized to develop thermal insulation coatings for the environmental protection purpose. The useful components of "three wastes" should be fully used to replace some heat insulation coatings raw materials, which could greatly reduce the cost and improve the environment. At the same time, the building heat insulation coatings performance evaluation and test methods of heat insulation performance should be formulated and improved, including the determination of coating thermal conduction, the real state simulation thermal insulation effect test, 
the qualitative and quantitative analysis of heat insulation coatings comprehensive index and heat insulation effect.

\section{Conclusions}

Due to the advantages of economic, construction convenient and good heat insulation effect, thermal insulation coating has gradually become a hot research topic, which could play an active role in the development of coatings market and heat insulation materials applications. This paper systematically summarized the related research progress and analyzed the main factors of thermal insulation coating. On the above basis, the development trend of thermal insulation coating in the future was also presented.

\section{Acknowledgements}

This research was financially supported by the National Natural Science Foundation of China (Grant no. 51404085), Key Technology R\&D Program of Tianjin city (Grant no. 15ZCZDSF00030), China Postdoctoral Science Foundation (Grant no. 2015M571255) and Natural Science Foundation of Hebei province (Grant no. E2014202276).

\section{References}

[1] W. Guo, X. Qiao, Y. Huang, et al., Study on energy saving effect of heat-reflective insulation coating on envelopes in the hot summer and cold winter zone, Energy and Buildings 50 (2012) 196-203.

[2] Y. Maryam, H. T. Amir, H. Babak, et al., Effect of heat treatment on magnetic properties of iron-based soft magnetic composites with $\mathrm{Al}_{2} \mathrm{O}_{3}$ insulation coating produced by sol-gel method, Journal of Alloys and Compounds 581 (2013) 293-297.

[3] S. H. Song, P.Xiao, Relation of microstructural and compositional features to the electrical properties in degraded thermal barrier coating systems, Journal of materials science 38 (2003) 1661-1665.

[4] S. K. Kesavan, R. A. Eastham, Selected Patents Related to Thermal Spraying, Journal of Thermal Spray Technology 12 (2003) 342-349.

[5] S. Kiil, Quantitative analysis of silica aerogel-based thermal insulation coatings, Progress in Organic Coatings 89 (2015) 26-34.

[6] H. Shen, Nonlinear thermal bending of FGM cylindrical panels resting on elastic foundations under heat conduction, Composite Structures 113 (2014) 216-224.

[7] F. Yan, P. Lin, X. Li, Research and application of BG water thermal insulation coating, Building energy saving 11 (2005) 40-43.

[8] M. Li, B. Liang, X. Li, et al., Development and production of multifunctional external wall thermal insulation coatings, Chemical building materials 22(2005) 40-41.

[9] D. E. Cagliostro, U.S. Patent 5939141. (1999)

[10] M. Santamouris, K. Pavlou, A. Synnefa, et al., Recent progress on passive cooling techniques advanced technological developments to improve survivability levels in low-income households, Energy and Buildings 39(2007) 859-866.

[11] N. R. Nelson, U.S. Patent 5445754. (1995)

[12] C. X. Zhang, C. G. Zhou, H. Peng, et al., Influence of thermal shock on insulation effect of nano-multilayer thermal barrier coatings, Surface and Coatings Technology 201 (2007) 6350-6344. 
[13] X. Hong, Development of space reflective thermal insulation coatings, New type building materails 32 (2004) 46-47.

[14] N. Guo, Development of polyurethane modified chloroacylic resin solar- heat reflective paint, Modern paint and finishing 1 (2003) 6-9.

[15] C. Ma, CN Patent 1583908A. (2005)

[16] G. Hugo, U.S. Patent 6017981. (2000)

[17] O. Naoto, Hisao H, Masahiro K, Japan Patent 2001262072. (2001)

[18] M. Kiik, R. J. Tobin, L. T. Hahn, et al., U.S. Patent 6872440. (2005)

[19] C. B. Jing, J. X. Hou, Fabrication and optical characteristics of thick $\mathrm{GeO}_{2}$ sol-gel coatings, Optical Material 30(2008) 857-864.

[20] D. C. Romonţi, J. Iskra, M. Bele, et al., Elaboration and characterization of fluorohydroxyapatite and fluoroapatite sol-gel coatings on CoCrMo alloy, Journal of Alloys and Compounds 665 (2016) 355-364.

[21] G. Shao, X. Wu, Y. Kong, et al., Thermal shock behavior and infrared radiation property of integrative insulations consisting of $\mathrm{MoSi}_{2}$ /borosilicate glass coating and fibrous $\mathrm{ZrO}_{2}$ ceramic substrate, Surface and Coatings Technology 270 (2015) 154-163.

[22] C. Feng, J. Chen, X. Hu, et al., Study on radiation type heat insulation coatings, Journal of Changshu Institute of Technology 21 (2007) 75-79.

[23] J. Wang, G. Lu, Solar heat reflective insulation coating, Coating Industry 34 (2004) 17-20.

[24] X. Wang, Y. Zhou, Preparation and properties of collagen indium tin oxide composite infrared low emissivity coatin, Materials Protection 40 (2007) 40-43.

[25] H. Luo, J. Cha, CN Patent 1569976. (2005)

[26] R. O. Loutfy, E. M. Wexler, Advanced thermal protection coating using fullerenes, perspectives of fullerene nanotechnology[M]. Springer Netherlands, 2002: 267-273.

[27] R. Scott, S. D. Cherico, High-emssivity coating teclnology improves annealing furnace efficiency, Iron Steel Technol 4 (2007) 319-324.

[28] Y. Ishihara, T. Hirai, C. Sakurai, et al., Applications of the particle ordering technique for conductive anti-reflection films, Thin Solid Films 411 (2002) 50-55.

[29] G. Chen, W. Tu, J. Cheng, Study on reflective solar thermal coatings, Coating Industry 32 (2002) 3-5.

[30] W. Zhan, Y. Deng, S. Chen, Study on reflective insulation coatings for buildings, Modern paint and finishing 2 (2001) 12-14.

[31] H. David, Protecting the Roof That Protects You, Construction Repaire 3 (1989) 24-25. 